University of Wollongong

Research Online

Faculty of Engineering and Information

Faculty of Engineering and Information

Sciences - Papers: Part A

Sciences

$1-1-2013$

Investigation on slab continuous straightening technology and deformation analysis

Xingzhong Zhang

Yanshan University, xingzhon@uow.edu.au

Hongtao Zhu

University of Wollongong, hongtao@uow.edu.au

Wen Huang

Yanshan University

Baojun Shi

CITIC Dicastal Wheel Manufacturing Co. Ltd., shi050214@126.com

Anh Kiet Tieu

University of Wollongong, ktieu@uow.edu.au

Follow this and additional works at: https://ro.uow.edu.au/eispapers

Part of the Engineering Commons, and the Science and Technology Studies Commons

Research Online is the open access institutional repository for the University of Wollongong. For further information contact the UOW Library: research-pubs@uow.edu.au 


\title{
Investigation on slab continuous straightening technology and deformation analysis
}

\author{
Abstract \\ A new method of setting continuous bending and straightening strain rate according to temperature \\ subzone was brought forward. By making use of the high temperature creep character effectively during \\ the continuous casting slab being straightened, a new model curve of continuous caster was developed. \\ And by using theoretical and finite element method the strain and strain rate of the slab under multi-point \\ straightening and the new continuous straightening were analysed. The result shows that for continuous \\ straightening the strain rate of the slab is constant and lower than that of the slab under multi-point \\ straightening, and the strain varies linearly. It is verified that the new continuous straightening technology \\ is reasonable and superior.

\section{Keywords} \\ deformation, analysis, technology, straightening, investigation, slab, continuous \\ Disciplines \\ Engineering | Science and Technology Studies \\ Publication Details \\ Zhang, X., Zhu, H., Huang, W., Shi, B. \& Tieu, A. Kiet. (2013). Investigation on slab continuous straightening \\ technology and deformation analysis. International Journal of Materials and Product Technology, 47 (1-4), \\ 126-137.
}




\title{
Investigation on slab continuous straightening
} technology and deformation analysis

\author{
Xingzhong Zhang* \\ National Engineering Research Center for \\ Equipment and Technology of Cold Strip Rolling, \\ Yanshan University, \\ Qinhuangdao, Hebei, 066004, China \\ E-mail: zhangxzh@ysu.edu.cn \\ *Corresponding author

\section{Hongtao Zhu}

School of Mechanical, Materials and Mechatronic Engineering,

University of Wollongong,

Wollongong NSW 2522, Australia

E-mail: hongtao@uow.edu.an

\section{Wen Huang}

National Engineering Research Center for

Equipment and Technology of Cold Strip Rolling,

Yanshan University,

Qinhuangdao, Hebei, 066004, China

E-mail: huangwen@ysu.edu.cn

\section{Baojun Shi}

CITIC Dicastal Wheel Manufacturing Co. Ltd., Qinhuangdao, Hebei, 066000, China

E-mail: 448490354@qq.com

\section{Anh Kiet Tieu}

School of Mechanical, Materials and Mechatronic Engineering,

University of Wollongong,

Wollongong NSW 2522, Australia

E-mail: ktieu@uow.edu.au

\begin{abstract}
A new method of setting continuous bending and straightening strain rate according to temperature subzone was brought forward. By making use of the high temperature creep character effectively during the continuous casting slab being straightened, a new model curve of continuous caster was developed. And by using theoretical and finite element method the strain and strain rate of the slab under multi-point straightening and the new continuous
\end{abstract}


straightening were analysed. The result shows that for continuous straightening the strain rate of the slab is constant and lower than that of the slab under multi-point straightening, and the strain varies linearly. It is verified that the new continuous straightening technology is reasonable and superior.

Keywords: continuous casting; continuous straightening; finite element method; strain; strain rate.

Reference to this paper should be made as follows: Zhang, X., Zhu, H., Huang, W., Shi, B. and Tieu, A.K. (2013) 'Investigation on slab continuous straightening technology and deformation analysis', Int. J. Materials and Product Technology, Vol. 47, Nos. 1/2/3/4, pp.126-137.

Biographical notes: Xingzhong Zhang is a Professor of College of Mechanical Engineering at Yanshan University, Qinhuangdao, China. His research is concentrated on steelmaking and iron-making techniques and machinery design theory with a particular interest in steel continuous casting techniques and metallurgical machinery design. Major emphasis of his research has been on the mould oscillation technique and heat transfer of steel continuous casting.

Hongtao Zhu obtained his BEng in 1993, MEng in 1996, PhD in 2000 from Northeastern University, China. After completing his $\mathrm{PhD}$, he worked as a Postdoctoral Research Fellow in Shanghai Jiao Tong University for two years. Since 2003, he worked at the University of Wollongong (UOW), Australia as a Research Fellow. Since 2013, he works as a Lecturer at the School of Mechanical, Materials and Mechatronic Engineering, UOW. His major interests include tribology and lubrication, plate/strip rolling theory, fracture control in pipeline, numerical modelling, wheel and rail contact and battery management system for electric vehicles. He has authored/co-authored 74 refereed journal and 59 conference papers. As a CI, he has been awarded six competitive research grants from Australian Research Council (ARC) and Cooperative Research Centre (CRC).

Wen Huang is an Adjunct Professor of College of Mechanical Engineering at Yanshan University, Qinhuangdao, China. He received his $\mathrm{PhD}$ form Tohoku university, Japan, in 2003 with his research on computational mechanics and material. In recent years, he has been doing research on the metal plastic forming and application of heat transfer in steel continuous casting.

Baojun Shi is an Engineer in CITIC Dicastal Wheel Manufacturing Co. Ltd., Qinhuangdao, China. He received his MEng in Machinery Design and Theory from Yanshan University, Qinhuangdao, China, in 2011. Currently, he is working on the machining and manufacturing processes for the aluminium alloy wheels used in automobile.

Anh Kiet Tieu is currently a Professor of Mechanical Engineering, University of Wollongong. After graduating with a $\mathrm{PhD}$ degree from the University of Western Australia in 1975, he became an Investigation Engineer with BlueScope Steel for eight years, and then joined the University of Wollongong in 1982. His research interests are in tribology and computational mechanics in metal forming.

This paper is a revised and expanded version of a paper entitled 'Investigation on slab continuous straightening technology and deformation analysis' presented at the 15th International Conference on Advances in Materials and Processing Technology, AMPT2012, Wollongong, Australia, 23-26 September 2013. 


\section{Introduction}

Continuous steel casting is an important part in steel production, the technique of slab continuous straightening is the key technology to develop high efficiency continuous casting, of which the connotation is a high casting speed as the core, high-quality, defect free production as the basis to achieve high continuous casting rate, high operating rate. Arc and straight arc continuous casters are the main model in present steel continuous casting production. The slab has to undergo the straightening process in both two models. As for straight arc continuous casters, the slab is also undergoing a bending process. It is easy to generate cracks during the straightening or bending process, which is a major factor affecting the quality of slab. Thus, the crack is directly affected by method of straightening and bending. With the development of modern casting to high-speed casting, slab straightening developed from solid straightening to liquid-core straightening, along with single-point straightening to multi-point straightening, continuous straightening. Cracks may appear at the slab surface and the interface between two phases when being straightened or bended. The generation of the crack is related to the strain and strain rate while bending and straightening. The higher the strain and strain rate are, the lower the ultimate strength is, the more prone to generate crack. In order to avoid cracks, strain and strain rate should be minimised.

In the designing process of the straightening, plastic deformation was considered only while creep deformation is ignored. Yet the slab shows strong creep characteristics when in high temperature. Many researches have been done in the deformation of straightening and the generation of cracks of the slab. Suzuki et al. (1988) and Boitsov and Danilov (1988) had done research about the creep characteristics of steel under casting temperature, the bulging deformation of slab, the generation of cracks, etc. Pascon et al. (2006) and Pascon and Habraken (2007) had done some research works on the straightening of slab and crack defect. Mintz and Crowther (2010) had done analysis on the thermoplastic along with its relationship with cross crack of the slab. Lagerstedt and Fredriksson (2005) had established a prediction model of cracks in solidifying shell. Sevcika and Sevcikovab (2008) had done research works about the plasticity of low carbon steel above $1,200^{\circ} \mathrm{C}$. Calvo and Rezaeian (2007) had done researches about the hot ductility and the mechanism of the generation of crack. Niu et al. (2011) had done the research work on the temperature field of the slab, mechanism of the generation of crack and countering measures. Wang et al. $(2003,2005)$ had done tests and researches about high temperature properties of continuous casting high carbon steels, internal cracks and stress and strain during solidifying process. Feng et al. (2009) and Cai and Zhu (2011) had done research works on the solidifying of the slab, strain in straightening process. These researches indicated that high temperature creep of the steel has significant influence on the deforming of the slab, which cannot be overlooked in straightening and bending process.

As for continuous straightening, Concast Corporation and voestalpine AG first proposed continuous straightening (bending) method, Concast Corporation proposed a straightening method using floating rollers to deform the slab, which automatically adapts to straightening curves, along with cube curve straightening method. Voestalpine AG proposed executing continuous straightening with fixed rolls. Sheng et al. (1997) proposed three-segment-curve straightening method, which modified Concast continuous straightening method. Zeng et al. (2006) had analysed the limitation of Concast curve and 
proposed using convolute curve as continuous straightening curve. Li (1996), Man and Li (2008) and Man et al. (2008) had done researches about using the high temperature character in continuous straightening process, the high temperature creep and the stress relaxation of slab, also proposed a late-model continuous straightening curve with two continuous straightening areas. The researches indicated that during bending or straightening process, slab in high temperature with lower strain and strain rate is less likely to generate cracks.

The strain and strain rate of bending and straightening decreased due to continuous straightening, thus the high temperature creep deformation played a large role in the straightening process. The lower the strain and strain rate is, the larger the proportion of creep deformation in the total straightening deformation is. In order to maximise the use of the high temperature creep deformation during the slab straightening and bending process, the model curve of continuous caster was studied in this paper. The new model curve could make the slab bended and straightened in almost the whole second cooling segment before the straightening point. For example, for the straight arc casting machine, the slab is continuously bended just under the straight line segment and continuously straightened right after the bending. The basic arc segment was cancelled so that length of the bending and straightening area can be extended significantly, and bending and straightening strain and strain rate can be substantially reduced. Thus, crack can be avoided effectively and the speed of casting and the productivity of the caster can be increased significantly.

\section{Theory of high temperature creep}

During casting process, the slab temperature ranges from 1,500 to 800 degree. At this temperature, the slab shows strong creep properties. Under the same external force, slab deformation increases with time increasing, which is the high temperature creep.

In the process of continuous casting, the slab corresponds to the steady creep stage of creep curve, the general relationship between the strain rate and the stress is

$$
\dot{\varepsilon}=K \sigma^{n}
$$

where $K$ and $n$ is material constants.

Figure 1 Maxwell model

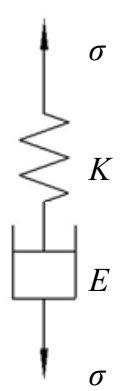


According to the material rheological theory, rheological model of high temperature slab can be Maxwell model which is shown in Figure 1 (Wan, 1985). Set the elastic and viscous components were stressed for $\sigma$, the strain of elastic and viscous components were $\varepsilon_{1}$ and $\varepsilon_{2}$ respectively, the strain rates were $\dot{\varepsilon}_{1}$ and $\dot{\varepsilon}_{2}$ respectively, there is

$$
\begin{aligned}
& \sigma=E \varepsilon_{1} \\
& \sigma=K \dot{\varepsilon}_{2}
\end{aligned}
$$

Total pulling strain rate in the system equals to the elastic strain rate plus the viscous strain rate, i.e.,

$$
\dot{\varepsilon}=\dot{\varepsilon}_{1}+\dot{\varepsilon}_{2}
$$

From equation (2) and equation (3), there is

$$
\frac{\sigma}{K}+\frac{\dot{\sigma}}{E}=\dot{\varepsilon}
$$

Equation (5) is the Maxwell rheological equation, and object meeting the equation are known as the Maxwell object. Slab in high temperature can be considered as Maxwell object.

At time $t$ equals 0 , load to the slab and keep the stress as constant $\sigma_{0}$. The solution of the equation (5) can be expressed as

$$
\varepsilon=\frac{\sigma_{0}}{K} t+\frac{\sigma_{0}}{E}
$$

Equation (6) is the Maxwell creep equation, where $\sigma_{0} / E$ is the strain when $t$ equals to 0 . The total strain $\varepsilon$ increases gradually with increasing of time $t$. After removing the initial stress $\sigma_{0}$, the second term is zero in equation (6), and the strain $\varepsilon=\left(\sigma_{0} / K\right) t$ is preserved permanently which is the creep strain of the slab. Giving full play to the influence of the creep during bending and straightening could effectively avoid bending straightening cracks in the slab.

Among current continuous bending and straightening methods, bending and straightening arcs are comparatively short which have not given full play to the role of the slab high temperature creep deformation during bending and straightening. In this paper, the basic arc of continuous casting machine is cancelled and the length of the bending and straightening areas are increased in which way the strains of bending and straightening have reduced dramatically. This method could give full play to the role of the slab high temperature creep deformation during bending and straightening.

\section{New model curve design of continuous casting machine}

In this paper, the R9300 straight arc slab casting machine of one steel mill is considered. Its main parameters are shown in Table 1. It uses five-point bending and five-point straightening following the straight section. There is a long basic arc segment between bending and straightening segments. The straightening radius of this casting machine are $R_{0}=9,300 \mathrm{~mm}, R_{1}=11,312.892 \mathrm{~mm}, R_{2}=14,671.987 \mathrm{~mm}, R_{3}=21,396.378 \mathrm{~mm}$, $R_{4}=41,581.549 \mathrm{~mm}$ and $R_{5}$ equals infinity. The bending radius are $R_{6}=49,420.834 \mathrm{~mm}$, 
$R_{7}=24,328.140 \mathrm{~mm}, R_{8}=15,971.287 \mathrm{~mm}, R_{9}=11,797.719 \mathrm{~mm}$ and $R_{0}=9,300 \mathrm{~mm}$. The mould length is $900 \mathrm{~mm}$, the straight line section length is $1,565 \mathrm{~mm}$, the bending section length is $1,030 \mathrm{~mm}$ and the straightening section length is $1,520 \mathrm{~mm}$.

Table 1 The main process parameters of continuous caster

\begin{tabular}{lccccc}
\hline $\begin{array}{l}\text { Process } \\
\text { parameters }\end{array}$ & $\begin{array}{c}\text { Casting } \\
\text { speed } \\
(\mathrm{m} / \mathrm{min})\end{array}$ & $\begin{array}{c}\text { Slab size } \\
(\mathrm{mm} \times \mathrm{mm})\end{array}$ & $\begin{array}{c}\text { Basic } \\
\text { arc radius } \\
(\mathrm{mm})\end{array}$ & $\begin{array}{c}\text { Casting } \\
\text { temperature } \\
\text { (degree })\end{array}$ & $\begin{array}{c}\text { Casting } \\
\text { machine } \\
\text { length }(\mathrm{m})\end{array}$ \\
\hline $\begin{array}{l}\text { Parameter } \\
\text { values }\end{array}$ & $1.4 \sim 1.65$ & $900 \sim 1,550 \times 230$ & 9,300 & 1,530 & 35.8 \\
\hline
\end{tabular}

Figure 2 New continuous bending and straightening curves (see online version for colours)

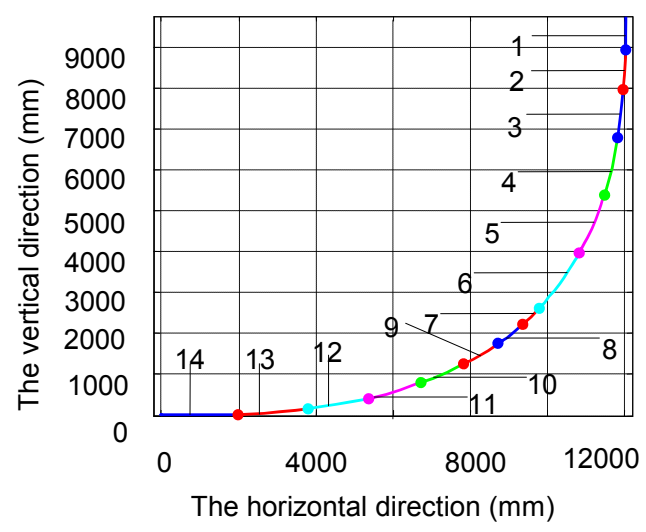

Table 2 The main parameters of continuous bending and straightening curves

\begin{tabular}{lccccc}
\hline & & $\begin{array}{c}\text { Arc length } \\
(\mathrm{mm})\end{array}$ & $\begin{array}{c}\text { Transition } \\
\text { radius }(\mathrm{mm})\end{array}$ & $\begin{array}{c}\text { Transition } \\
\text { radius }(\mathrm{mm})\end{array}$ & $\begin{array}{c}\text { Change rate } \\
\text { of curvature }\end{array}$ \\
\hline Bending \\
curve & Curve 1 & 800 & 21,000 & Infinity & $5.95238 \mathrm{E}-08$ \\
& Curve 2 & 1,000 & 14,000 & 21,000 & $2.38095 \mathrm{E}-08$ \\
& Curve 3 & 1,200 & 10,500 & 14,000 & $1.98413 \mathrm{E}-08$ \\
& Curve 4 & 1,400 & 8,400 & 10,500 & $1.70068 \mathrm{E}-08$ \\
\multirow{5}{*}{$\begin{array}{l}\text { Straightening } \\
\text { curve }\end{array}$} & Curve 5 & 1,600 & 7,000 & 8,400 & $1.4881 \mathrm{E}-08$ \\
& Curve 6 & 1,698 & 6,000 & 7,000 & $1.40246 \mathrm{E}-08$ \\
& Curve 7 & 600 & 6,000 & 6,750 & $3.08642 \mathrm{E}-08$ \\
& Curve 8 & 800 & 6,750 & 7,714 & $2.31481 \mathrm{E}-08$ \\
& Curve 9 & 1,000 & 7,714 & 9,000 & $1.85185 \mathrm{E}-08$ \\
& Curve 10 & 1,200 & 9,000 & 10,800 & $1.54321 \mathrm{E}-08$ \\
& Curve 11 & 1,400 & 10,800 & 13,500 & $1.32275 \mathrm{E}-08$ \\
& Curve 12 & 1,600 & 13,500 & 18,000 & $1.15741 \mathrm{E}-08$ \\
& Curve 13 & 1,800 & 18,000 & 27,000 & $1.02881 \mathrm{E}-08$ \\
& Curve 14 & 2,000 & 27,000 & Infinity & $1.01185 \mathrm{E}-08$ \\
\hline
\end{tabular}


According to this continuous casting machine, combined with the consideration of the high temperature creep deformation characteristics of steel, the new bending and straightening curves of continuous casting machine has been developed by the method of connecting multi-segment curves smoothly, shown in Figure 2. For the new curves, six smoothly connected curves, of which curvatures are changing continuously, are used as bending curve of slab just under the straight segment. At the same time, eight smoothly connected curves, of which curvatures are changing continuously also, are used as straightening curve of slab. The basic arc was cancelled. The bending curve and straightening curve are connected smoothly. Parameters of each curve are shown in Table 2 .

\section{Straightening strain and strain rate calculation}

\subsection{Strain rate at the solid-liquid boundary}

Because the bending deformation and straightening deformation of slab are similar, the straightening deformation analysis is discussed here only.

The solidified shell thickness can be calculated using equation (7)

$$
\delta=k \sqrt{l / v_{c}}
$$

where $k$ is solidification coefficient and equals $26.5 \mathrm{~mm} / \mathrm{min}^{1 / 2}, l$ is the distance from the meniscus in $\mathrm{m}, v_{c}$ is casting speed in $\mathrm{m} / \mathrm{min}$.

According the theory of multi-point straightening of slab, the strain rate at solid-liquid two phase interface can be calculated using equation (8) with ignoring the gravity of the slab,

$$
\dot{\varepsilon}=\frac{(D / 2-\delta)\left(1 / R_{i}-1 / R_{i+1}\right)}{t}
$$

where $D$ is slab thickness in mm, $R_{i}$ and $R_{i+1}$ are the curvature radius of the starting point and the end point of straightening curve in $\mathrm{mm}, t$ is deformation time in $\mathrm{s}$.

Figure 3 The strain rate at solid-liquid boundary of straightening area (see online version for colours)

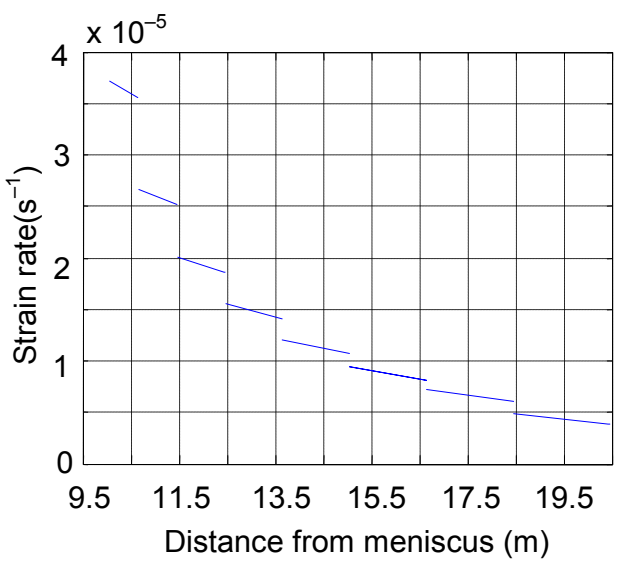


Figure 4 The strain rate at solid-liquid boundary for five-point straightening section

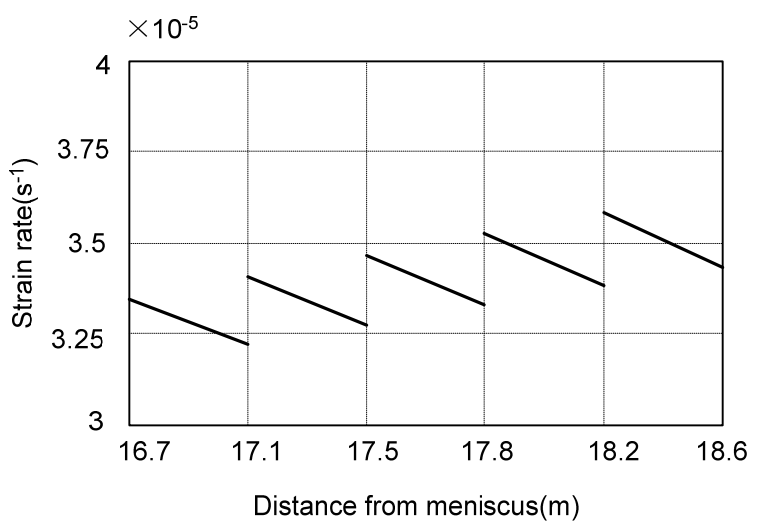

For the continuous straightening, the strain rate at solid-liquid two phase interface of each straightening segment can be calculated using equation (8) approximately. At the casting speed of $1.5 \mathrm{~m} / \mathrm{min}$, the straightening strain rates at the solid-liquid two phase interface of the continuous straightening and the original five-point straightening are calculated using equation (8), and the result are shown in Figure 3 and Figure 4.

It can be seen from Figure 3 and Figure 4 that the straightening equivalent strain rate of continuous straightening is smaller than that of the original multi-point straightening. The deformation rate of bending segment has the same characteristic.

\subsection{Strain and strain rate at the surface of slab}

This section is mainly about the variation law of surface strain and surface strain rate of the multi-point straightening and the new continuous straightening. Through the comparison, the superiority of the new continuous straightening technology has been verified.

Figure 5 The finite element model (see online version for colours)

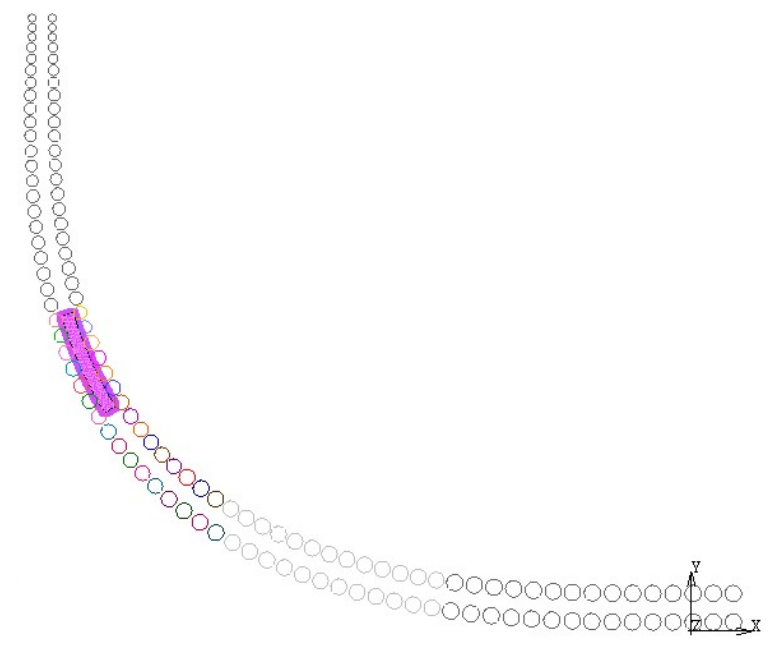


In order to analyse the straightening strain and strain rate of the slab surface, the finite element model was build which is shown in Figure 5. In this model, the rollers are set along the new continuous bending and straightening curves and the original multi-point bending and straightening curves separately. The size of the slab model is $2,000 \mathrm{~mm} \times$ $500 \mathrm{~mm} \times 230 \mathrm{~mm}$. During finite calculation, the gravity of slab is neglected. So the strains caused by gravity and misplacement of rollers are ignored.

Figure 6 Straightening strain on the surface of slab (see online version for colours)

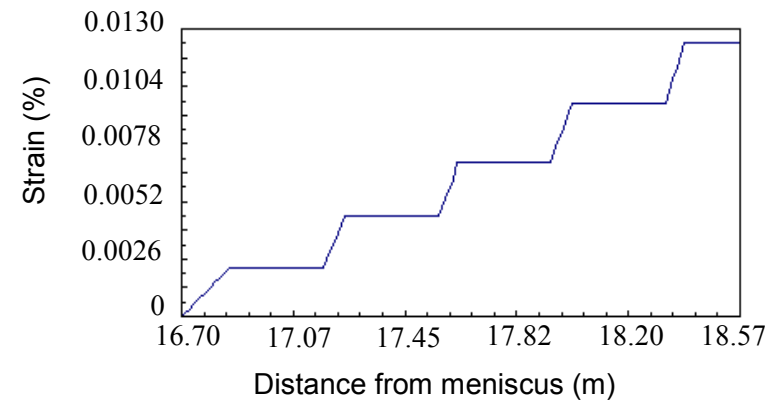

Figure 7 Straightening strain rate on the surface of slab (see online version for colours)

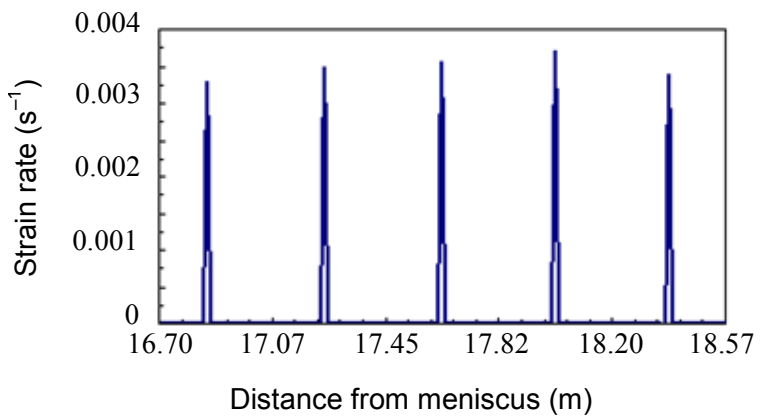

Figure 8 Straightening strain on the surface of slab

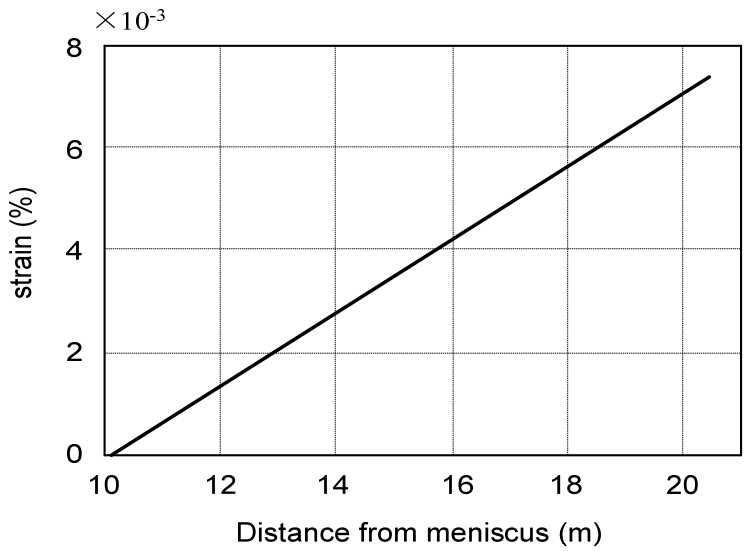


Figure 9 Straightening strain rate on the surface of slab

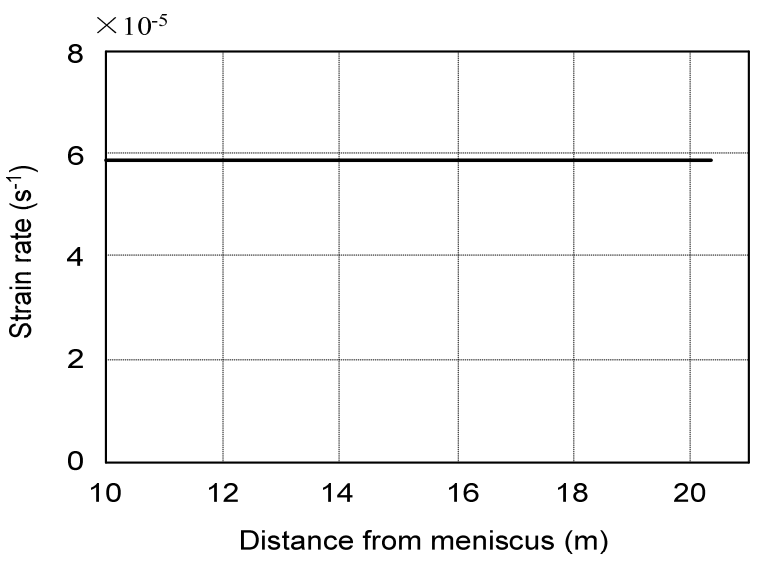

As the results, the straightening strain and straightening strain rate on the slab surface during continuous straightening and multi-point straightening are shown in Figure 6, Figure 7, Figure 8 and Figure 9. It can be seen that for the multi-point straightening, the straightening strain jumps ladder-like near the straightening point, the straightening strain rate also has large peak values with the maximum strain rate being about $3.75 \times 10^{-4} \mathrm{~s}^{-1}$, and for the continuous straightening the straightening strain changes linearly, the straightening strain rate is constant with the value of $5.88 \times 10^{-5} \mathrm{~s}^{-1}$.

It can be seen by comparing Figure 6 and Figure 8, Figure 7 and Figure 9 that the strain of continuous straightening changes slowly, and the strain rate is far less compared with that of multi-point straightening. So compared with multi-point straightening, the continuous straightening has superiority in preventing the straightening cracks happening.

\section{Conclusions}

The basic circular arc segment of traditional model was cancelled and the lengths of continuous bending and straightening areas were expanded in the new continuous bending and straightening method. Thus the strain rates of bending and straightening were reduced, the crack caused by bending and straightening could be effectively avoided, and the quality of the slab was improved. At the same time, this new bending and straightening method is adaptable for the high casting speed.

For the design of the new casting machine, by using this continuous bending and straightening technique, the height of the caster could be reduced, and the molten steel static pressure can be reduced, too, then it could result in the decrease of the bulging deformation of the slab. And as for the improvement of the existing continuous caster, the lengths of bending and straightening areas could be increased without changing the height of casting machine to realise continuous bending and straightening of slab. 


\section{Acknowledgements}

This research work is supported by National Natural Science Foundation of China under the Grant No. 51275446 and by the Hebei Provincial Natural Science Foundation of China under the Project No. E2012203080. The authors thank the National Science Foundation of China and Hebei Provincial Natural Science Foundation of China for funding of this research work.

\section{References}

Boitsov, Y.I. and Danilov, V.L. (1988) 'Investigation of creep and fracture in continuously cast steel', Steel in the USSR, Vol. 18, No. 7, pp.319-321.

Cai, Z.Z. and Zhu, M.Y. (2011) 'Simulation of thermal behavior during steel solidification in slab continuous casting mold', Acta Metallurgica Sinica, Vol. 46, No. 6, pp.671-677, 678-687.

Calvo, J. and Rezaeian, A. (2007) 'Effect of the thermal cycle on the hot ductility and fracture mechanisms of a C-Mn steel', Engineering Failure Analysis, Vol. 14, No. 2, pp.374-383.

Feng, L.H., Zhu, M.Y. and Liu, K. (2009) 'Study on the position of final solidifying end of continuous casting slab', Iron \& Steel, Vol. 44, No. 5, pp.23-26.

Lagerstedt, A. and Fredriksson, H. (2005) 'A model for prediction of cracks in a solidifying shell', Materials Science and Engineering A, Vols. 413-414, pp.37-43.

Li, X.K. (1996) 'Low-head continuous casting machine with two smooth continuous straightening areas', Iron and Steel, Vol. 31, No. 4, pp.31-35.

Man, Y and Li, X.K. (2008) 'Study about using the elevated temperature characteristics of steel during continuous straightening', Journal of Plasticity Engineering, Vol. 15, No. 6, pp.96-101.

Man, Y., Li, X.K. and Yang, L.D. (2008) 'Experimental research of elevated temperature creep and stress relaxation during continuous straightening', Materials Science Forum, Vols. 575-578, pp.7-13.

Mintz, B. and Crowther, D.N. (2010) 'Hot ductility of steels and its relationship to the problem of transverse cracking in continuous casting', International Materials Reviews, Vol. 55, No. 3, pp.168-196.

Niu, S., Zhang, X.Z. and Gan, Y. (2011) 'Formation mechanism and countering measures for transverse surface crack of continuous casting slabs', Special Steel, Vol. 32, No. 1, pp.19-22.

Pascon, F. and Habraken, A.M. (2007) 'Finite element study of the effect of some local defects on the risk of transverse cracking in continuous casting of steel slabs', Computer Methods in Applied Mechanics and Engineering, Vol. 196, Nos. 21-24, pp.2285-2299.

Pascon, F., Cescotto, S. and Habraken, A.M. (2006) '2.5D finite element model for bending and straightening in continuous casting of steel slabs', International Journal for Numerical Methods in Engineering, Vol. 68, No. 1, pp.125-149.

Sevcika, A. and Sevcikovab, J. (2008) 'Plasticity drop at temperatures above $1200^{\circ} \mathrm{C}$ in the cast state of low carbon steels and its analysis', Materials and Design, Vol. 29, pp.118-123.

Sheng, Y.P., Dong, S.H. and Sun, J.Q. (1997) 'Three-piece of curve straightening method for continuously cast billet', Iron and Steel, Vol. 32, No. 1, pp.32-35.

Suzuki, T., Tacke, K.H. and Wuennenberg, K. (1988) 'Creep properties of steel at continuous casting temperatures', Ironmaking and Steelmaking, Vol. 15, No. 2, pp.90-100.

Wan, Q.H. (1985) Rheology of Material, China Construction Industry Press, Beijin. 
Wang, X.H., Zhu, G.S. and Yu, H.X. (2005) 'High temperature properties of continuous casting high carbon steels', Journal of University of Science and Technology Beijing, Vol. 27, No. 5, pp.545-548.

Wang, X.H., Zhu, Z.Y., Zhang, L. et al. (2003) 'Longitudinal surface cracks on continuous casting slabs of $\mathrm{P}$ and $\mathrm{Cu}$ containing container steel', Journal of University of Science and Technology Beijing: Mineral Metallurgy Materials, Vol. 10, No. 4, pp.16-19.

Zeng, J., Yang, L.D. and Yang, C.W. (2006) 'Further discussion of bending and strengthening curve in CCM', Heavy Machinery, No. 5, pp.5-7. 